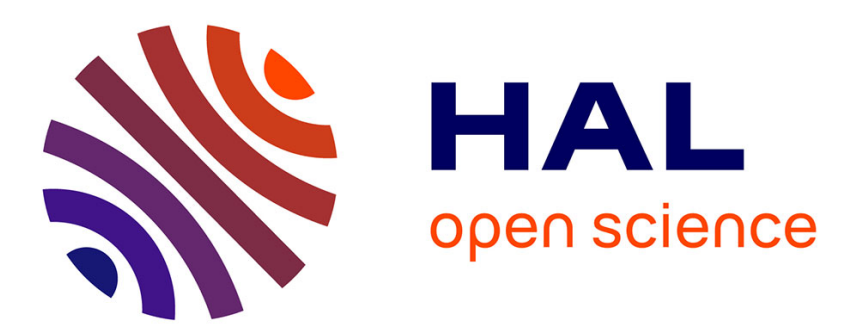

\title{
Structure of tetraalkylammonium ionic liquids in the interlayer of modified Montmorillonite
}

\author{
Daniel Duarte, Mathieu Salanne, Benjamin Rotenberg, M.A. Bizeto, Marcos
}

A Bizeto, Leonardo J. A. Siqueira

\section{- To cite this version:}

Daniel Duarte, Mathieu Salanne, Benjamin Rotenberg, M.A. Bizeto, Marcos A Bizeto, et al.. Structure of tetraalkylammonium ionic liquids in the interlayer of modified Montmorillonite. Journal of Physics: Condensed Matter, 2014, 26, pp.284107. hal-01078966

\section{HAL Id: hal-01078966 https://hal.sorbonne-universite.fr/hal-01078966}

Submitted on 6 Dec 2018

HAL is a multi-disciplinary open access archive for the deposit and dissemination of scientific research documents, whether they are published or not. The documents may come from teaching and research institutions in France or abroad, or from public or private research centers.
L'archive ouverte pluridisciplinaire HAL, est destinée au dépôt et à la diffusion de documents scientifiques de niveau recherche, publiés ou non, émanant des établissements d'enseignement et de recherche français ou étrangers, des laboratoires publics ou privés. 


\title{
Structure of tetraalkylammonium ionic liquids in the interlayer of modified Montmorillonite
}

\author{
Daniel Duarte ${ }^{1}$, Mathieu Salanne ${ }^{2}$, Benjamin Rotenberg ${ }^{2}$, \\ Marcos A Bizeto ${ }^{1}$ and Leonardo J A Siqueira ${ }^{1}$ \\ ${ }^{1}$ Laboratório de Materiais Híbridos, Departamento de Ciências Exatas e da Terra, Instituto de Ciências \\ Ambientais, Químicas e Farmacêuticas, Universidade Federal de São Paulo, CEP 09913-030, Diadema, \\ SP, Brazil \\ ${ }^{2}$ UPMC Univ Paris 06, CNRS, ESPCI, UMR 7195, PECSA, F-75005 Paris, France \\ E-mail: ljasiqueira@unifesp.br
}

\begin{abstract}
We perform molecular dynamics simulations of tetraalkylammonium ionic liquids confined in the interlayer of montmorillonite (MMT). We study the structure and energetics of the systems, which consist of cations with two different alkyl chain lengths and several ionic liquid concentrations. The results we obtained for the structure, namely the presence of a strong layering in all systems and the formation of nonpolar domains with interdigitated alkyl chains in some cases, are largely consistent with previous surface force balance experiments performed on similar systems. Finally, we show that swelling of the organo-modified MMT by a large amount of ionic liquid seems energetically favorable in all cases.
\end{abstract}

Keywords: ionic liquids, clay, interlayer structure

S Online supplementary data available from stacks.iop.org/JPhysCM/26/284107/mmedia

(Some figures may appear in colour only in the online journal)

\section{Introduction}

In the past decade inorganic materials with layered structures have been rediscovered as important precursors for the development of nanomaterials and nanostructures with innovative properties. This capability arises from their distinctive crystal structure, where the bonds among atoms that constitute the layers are stronger than the interaction that maintains the layers stacked. This feature confers intracrystalline reactivity to many layered materials. This means that they can undergo intercalation, pillaring and exfoliation reactions. The exfoliation is the final step of an intercalation reaction that promotes the layer separation to its extreme limit, where the interaction becomes weak enough to cause the crystal structure to collapse into individual layers called nanosheets. These two-dimensional single crystals have unique morphological features that allow them to be used to produce thin films, layerby-layer assemblies and hybrid nanostructures with innovative properties [1].
There are many classes of layered materials, grouped into different families with distinct intracrystalline reactivities and properties. Montmorillonite (MMT) is a layered compound that belongs to the smectite class of the clay family. It is a naturally occurring clay with a crystal structure built up by stacked negative charged layers with the interlayer space filled by hydrated inorganic cations, such as $\mathrm{Ca}^{2+}, \mathrm{Na}^{+}$and $\mathrm{K}^{+}$, that maintain the electroneutrality of the structure [2]. Each layer is built up by two tetrahedral silicate $\left(\mathrm{SiO}_{4}\right)$ sheets $(\mathrm{T})$, sandwiching an octahedral gibbsite-like $\left(\mathrm{AlO}_{6}\right)$ sheet $(\mathrm{O})$ in a TOT arrangement. The negative charge of the layer arises from the partial isomorphic substitution of the aluminum located in the octahedral sheet by bivalent cations, such as $\mathrm{Mg}^{2+}$, and the silicon from the tetrahedral sheet by trivalent cations, such as $\mathrm{Al}^{3+}$ and $\mathrm{Fe}^{3+}$.

When sodium ions are present as interlayer cations, one observes the spontaneous exfoliation of MMT in aqueous media, producing a thixotropic gel that is used as a drilling fluid 
for oil extraction and as a component of paints and cosmetic formulations [3]. Besides small inorganic cations, it is also possible to intercalate diverse types of organic cations into MMT, which allows the development of hybrid materials with unique properties and useful applications [4]. Clays, and especially MMT, have long been used as fillers for different polymeric matrices. The better compatibility of organoclays with polymeric matrices created an opportunity for the development of polymer nanocomposites with enhanced thermal, mechanical and gas barrier properties compared to conventional polymer composites [5,6]. Due to the high commercial impact and demand for this kind of advanced material, different types of organic species have been evaluated as clay modifiers for the polymer nanocomposite production, including ionic liquids (ILs) [7-9]. ILs may have interesting properties in this context, due to the particular structure that they adopt at interfaces [10-18]. The immobilization of ILs into solid matrices is of particular interest for the development of solid electrolytes for fuel and solar cells [19-21]. Layered materials intercalated with ILs are good candidates for the production of solid electrolytes, since the interlayer region might accommodate the IL, maintaining its ionic conductivity property but also improving the thermal and chemical stabilities [5, 9].

The intercalation of IL into layered compounds has already been reported in metallic hydroxides [22], zirconium phosphate [23, 24], vanadium pentoxide [25], titanium disulfide [26], kaolinite [27], MMT [9, 28-35], and layered double hydroxides [34]. However, the results reported indicate that much more effort is required in their synthesis to achieve the co-intercalation of IL cations and anions in layered compounds with charged layers. Cation and anion co-intercalation in clays or clay-like materials has only been achieved in modified kaolinite [27, 36, 37] and layered silicates [38], both with neutral layers. The IL-intercalated kaolinite presents some ionic conductivity [39] and can be used as electrode modifier [40] and in electrochemical sensors [41].

In the case of clays with negative charge layers, such as MMT, one observes only cation intercalation as a rule [9, 28-34]. Such clays exchanged by organic cations have been investigated via molecular simulations by Tambach et al, who found, for example, a gradual increase in the basal spacing for alkylammonium with increasing chain lengths [42]. However, recent surface force balance experiments indicate the presence of distinct structural features involving both organic cations and anions between mica surfaces [43]. Since mica is another member of the TOT clay minerals family, these experimental results suggest that understanding the structure of ILintercalated MMT could provide insights into the possibility of exfoliation of MMT by ILs. In the present study, we thus investigate the structural arrangement of tetraalkylammoniumbased ILs in organo-modified-MMT using molecular dynamics simulation.

\section{Computational details}

The MD simulations were performed considering a MMT modified with two different tetraalkylammonium cations
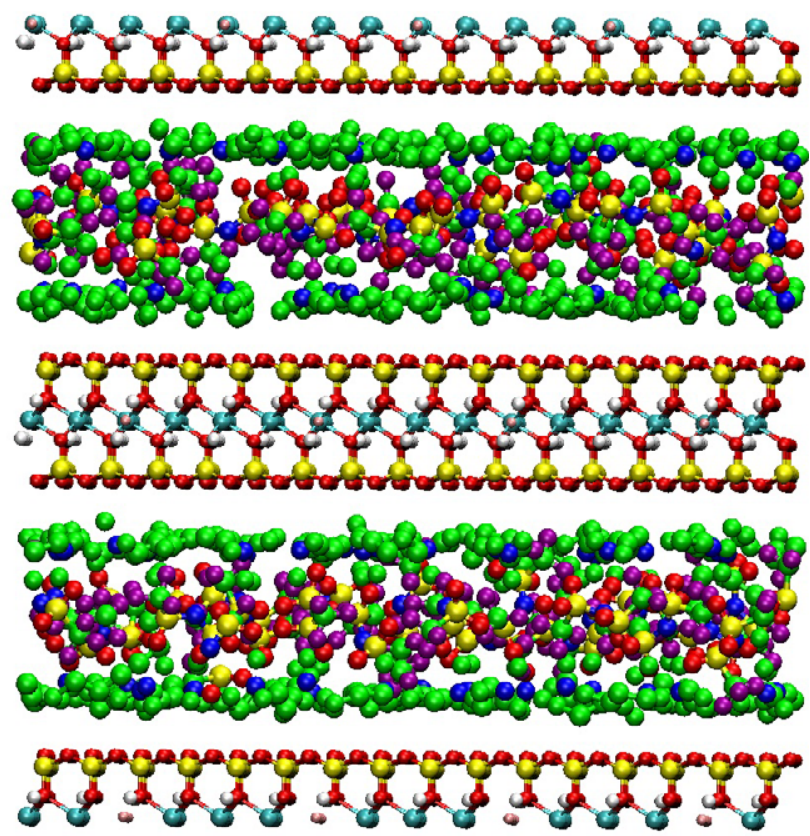

Figure 1. Snapshot of a typical simulation box with 50 ion pairs of $\mathrm{C}_{1} \mathrm{C}_{1} \mathrm{C}_{1} \mathrm{NC}_{4}-\mathrm{NTf}_{2}$ (yellow: $\mathrm{Si}$ inside the clay layer or $\mathrm{S}$ inside the interlayer, turquoise: $\mathrm{Al}$, red: $\mathrm{O}$, white: $\mathrm{H}$, blue: $\mathrm{N}$, violet: $\mathrm{F}$, green: C). The $z$ axis corresponds to the direction perpendicular to the basal surface.

(trimethylbutylammonium, $\mathrm{C}_{1} \mathrm{C}_{1} \mathrm{C}_{1} \mathrm{NC}_{4}$, and trimethyldecylammonium, $\left.\mathrm{C}_{1} \mathrm{C}_{1} \mathrm{C}_{1} \mathrm{NC}_{10}\right)$. Each layer of MMT consists of one octahedral sheet (aluminum oxide) sandwiched by two tetrahedral sheets (silicon oxide). The negative charge of MMT is obtained by replacing some $\mathrm{Al}^{3+}$ ions in the octahedral sheet by $\mathrm{Mg}^{2+}$, which is compensated by the equivalent amount of monovalent trimethylalkylammonium cations. The idealized unit cell formula of MMT is $\mathrm{C}_{0.75} \mathrm{Si}_{8}\left(\mathrm{Al}_{3.25} \mathrm{Mg}_{0.75}\right) \mathrm{O}_{20}(\mathrm{OH})_{4}$ and its atomic structure was that used in previous $\mathrm{MD}$ simulations $[44,45]$. The $x$ and $y$ dimensions of the simulation boxes are 3.588 and $4.144 \mathrm{~nm}$, corresponding to $4 \times 8$ unit cells. The simulation boxes contain two layers, one layer in the middle of the $z$-axis and two half-layers at the end of the $z$ direction. Forty-eight tetraalkylammonium cations, equally divided into the two interlayer spaces, compensate the negative charge of the surface. We consider two ionic liquids formed by either $\mathrm{C}_{1} \mathrm{C}_{1} \mathrm{C}_{1} \mathrm{NC}_{4}$ or $\mathrm{C}_{1} \mathrm{C}_{1} \mathrm{C}_{1} \mathrm{NC}_{10}$ cations associated with the bis[(trifluoromethane)sulfonyl]amide $\left(\mathrm{NTf}_{2}\right)$ anion in the interlayer space of modified MMT. The number of ion pairs and the corresponding number density of ion pairs $\mathrm{nm}^{-2}$ are shown in table $\mathrm{S} 1$ of the supplementary information (available at stacks.iop.org/JPhysCM/26/284107/mmedia). A snapshot of a typical simulation box, in the case of the $\mathrm{C}_{1} \mathrm{C}_{1} \mathrm{C}_{1} \mathrm{NC}_{4}$ counterion, is provided in figure 1 .

Non-bonded interactions between all atoms are described by pairwise potentials,

$$
U_{i j}^{\text {nonbonded }}=\frac{1}{4 \pi \varepsilon_{0}} \frac{q_{i} q_{j}}{r_{i j}}+4 \varepsilon_{i j}\left[\left(\frac{\sigma_{i j}}{r_{i j}}\right)^{12}-\left(\frac{\sigma_{i j}}{r_{i j}}\right)^{6}\right]
$$

where $r_{i j}$ is the distance between atoms $i$ and $j, q_{i}$ is the partial charge of atom $i, \varepsilon_{0}$ is the vacuum permittivity, 
and $\varepsilon_{i j}$ and $\sigma_{i j}$ are Lennard-Jones parameters. Non-bonded interactions are also considered for atoms separated by at least three bonds within a single molecular ion, with a scaling factor of $f=0.5$. The parameters for non-bonded interactions are provided in table S2 of the supplementary information (available at stacks.iop.org/JPhysCM/26/284107/ mmedia). Lennard-Jones parameters for different atom types are obtained using the Lorentz-Berthelot mixing rules. The $\mathrm{CH}_{3}$ and $\mathrm{CH}_{2}$ groups of cations are considered as a single force center, meaning $\mathrm{H}$ atoms are not taken into account explicitly. Usual bond stretching, angle bending, and dihedral torsion potentials were considered for intramolecular interactions, whose equations and parameters are provided in tables S3 to S6 in the supplementary information (available at stacks.iop. org/JPhysCM/26/284107/mmedia). The parameters for MMT correspond to the CLAYFF force field [46]. Apart from the partial charges of cations, the parameters for $\mathrm{C}_{1} \mathrm{C}_{1} \mathrm{C}_{1} \mathrm{NC}_{4}$ and NTf2 are those used in previous MD simulations of ionic liquids [47-50]. In the case of the $\mathrm{C}_{1} \mathrm{C}_{1} \mathrm{C}_{1} \mathrm{NC}_{1} 0$ cation, their parameters were those used in previous simulations of tetraalkylammonium surfactants $[51,52]$. The interaction potential used in the present simulations does not include polarization effects. In ionic liquids or molten salts, the latter impact the transport properties but do not notably influence the structure of the systems [53-55], so that our results should remain unaffected by this choice.

Initial configurations of ions are first generated with the program PACKMOL [56] to place the ions into the two interlayer spaces of MMT. Then, the interlayer distance is progressively shrunk until an equilibrium pressure of 1 atm at $300 \mathrm{~K}$ is reached. Finally, the systems are equilibrated further for $1 \mathrm{~ns}$ in the NVT ensemble, before $2 \mathrm{~ns}$ production runs with a time step of 1 fs. All MD simulations are performed using the DLPOLY package [57]. The system is maintained at $300 \mathrm{~K}$ with the Berendsen thermostat with a relaxation time of 2 ps and the equation of motion of ions is integrated using the leapfrog algorithm. The Ewald summation method is used to deal with long-range electrostatic interactions, using a precision of $10^{-6}$. Short-range and Ewald summation cut-off radii of 1.33 and $1.53 \mathrm{~nm}$ are used for the $\mathrm{C}_{1} \mathrm{C}_{1} \mathrm{C}_{1} \mathrm{NC}_{4}$ and $\mathrm{C}_{1} \mathrm{C}_{1} \mathrm{C}_{1} \mathrm{NC}_{10}$ cations, respectively.

\section{Results and discussion}

\subsection{Basal spacing}

The modification of a clay's interlayer space with organic cations by ion exchange reaction is well documented, both experimentally $[9,28-35]$ and computationally [42, 58-60]. The interlayer of modified clay changes with the size of the filling cation and also with the cation exchange capacity, CEC, of the clay. For instance, for MMT $(\mathrm{CEC}=90$ mequiv $/ 100 \mathrm{~g})$ modified with $\mathrm{C}_{1} \mathrm{C}_{1} \mathrm{C}_{1} \mathrm{NC}_{4}$ and $\mathrm{C}_{1} \mathrm{C}_{1} \mathrm{C}_{1} \mathrm{NC}_{10}$ cations, basal spacings, calculated by the distance between $\mathrm{Al}$ atoms in different layers, of 1.40 and $\sim 1.55 \mathrm{~nm}$ were respectively obtained in a previous MD simulation study [58]. Accordingly, in our simulations in which the same cations were considered, but with a united atom model and a different force field, the corresponding spacings are 1.33 and $1.54 \mathrm{~nm}$, respectively. When filling progressively the interlayer with ion pairs of the

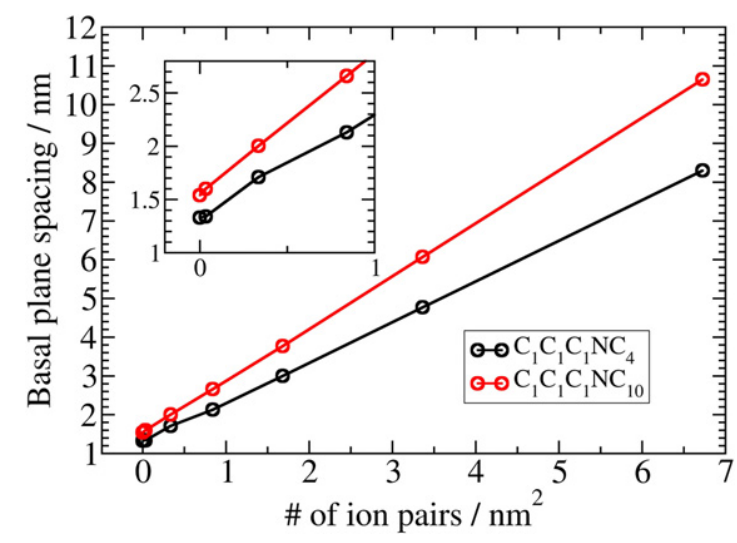

Figure 2. Basal plane spacing of MMT calculated by the $\mathrm{Al}-\mathrm{Al}$ distance in the simulations of $\mathrm{C}_{1} \mathrm{C}_{1} \mathrm{C}_{1} \mathrm{NC}_{4}-\mathrm{NTf}_{2}$ and $\mathrm{C}_{1} \mathrm{C}_{1} \mathrm{C}_{1} \mathrm{NC}_{10}-\mathrm{NTf}_{2}$ ionic liquids at $300 \mathrm{~K}$ and $1 \mathrm{~atm}$. In order to obtain the density of ion pairs, we divided the number of ion-pairs by the total basal surface, $A . A=[4 \times$ (number of surfaces in contact with the ions) $\times 3.588 \mathrm{~nm} \times 4.144 \mathrm{~nm}]$.

$\mathrm{C}_{1} \mathrm{C}_{1} \mathrm{C}_{1} \mathrm{NC}_{10}-\mathrm{NTf}_{2}$ ionic liquid the MMT basal plane spacing increases linearly with the number of ion pairs. This is also true for the $\mathrm{C}_{1} \mathrm{C}_{1} \mathrm{C}_{1} \mathrm{NC}_{4}-\mathrm{NTf}_{2}$ ionic liquid, but for a density greater than 1 ion pair $\mathrm{nm}^{-2}$, as shown on figure 2 . The inset of figure 2 shows the interlayer space between 0 and 1 ion pairs $\mathrm{nm}^{-2}$. A slight deviation from a straight line is observed in the interlayer space of MMT when filled with $\mathrm{C}_{1} \mathrm{C}_{1} \mathrm{C}_{1} \mathrm{NC}_{4}-\mathrm{NTf}_{2}$ ionic liquid due to the presence of three layers of ions- that is, one layer of anions between the two layers of cations adsorbed on the MMT surface (figure 3(C)). In the case of $\mathrm{C}_{1} \mathrm{C}_{1} \mathrm{C}_{1} \mathrm{NC}_{10}-\mathrm{NTf}_{2}$, the swelling slope is steeper because it has lower density than $\mathrm{C}_{1} \mathrm{C}_{1} \mathrm{C}_{1} \mathrm{NC}_{4}-\mathrm{NTf}_{2}$.

\subsection{Structure of organo-modified MMT with low IL content}

When studying the structure of the tetraalkylammonium cations in the interlayer region, we need to examine separately the head groups, which concentrate most of the charge, and the butyl chains. The corresponding density profiles are reported in figure 3. In the modified MMT, the $\mathrm{C}_{1} \mathrm{C}_{1} \mathrm{C}_{1} \mathrm{NC}_{4}$ cations are arranged in such a way that the head groups form one layer of cations, with butyl chains parallel to the MMT slab, whereas two layers of head groups are formed with $\mathrm{C}_{1} \mathrm{C}_{1} \mathrm{C}_{1} \mathrm{NC}_{10}$ cations. In the latter case, a layered structure with apolar tails between two layers of charged heads (one on each surface) is observed, in accordance with previous work by Heinzet al [58]. Note also that a specific orientation of cations has also been observed in simulations of imidazolium-based ionic liquids adsorbed on electrodes [61, 62].

In the first considered system, with the addition of a small amount of IL, that is, one $\mathrm{C}_{1} \mathrm{C}_{1} \mathrm{C}_{1} \mathrm{NC}_{4}-\mathrm{NTf}_{2}$ ion pair per interlayer or 0.0336 ion pair $\mathrm{nm}^{-2}$, the extra cation and anion are accommodated in the same layer, with the C-S-N-S-C chain of anions also parallel to the MMT slab, as shown in the number density profiles provided in figure 3(A). In the case of MMT modified with $\mathrm{C}_{1} \mathrm{C}_{1} \mathrm{C}_{1} \mathrm{NC}_{10}$, the chain C-S-N-S-C of the $\mathrm{NTf}_{2}$ anion is mostly located in the apolar layer, between the two layers of cation head groups (figure $3(\mathrm{~B})$ ). This is due to this 


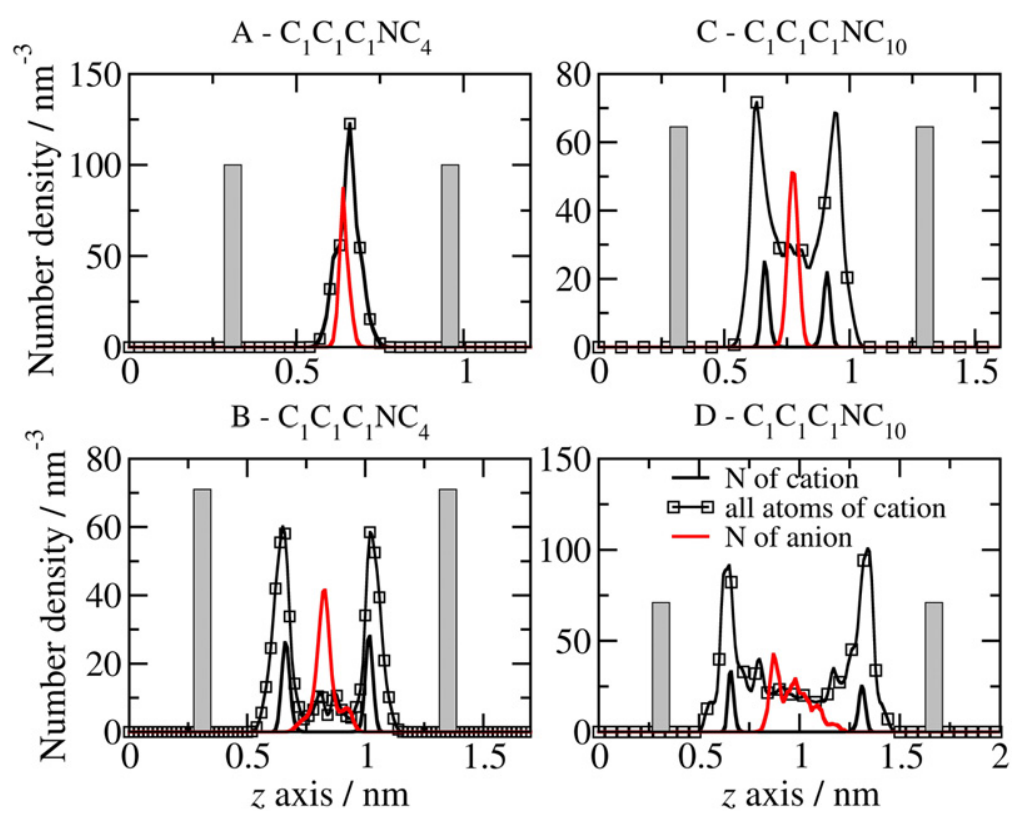

Figure 3. Number density profiles of cations (black) and anions (red) calculated for modified MMT with densities of 0.0336 ((A) and (C)) and $0.336((\mathrm{~B})$ and $(\mathrm{D}))$ ion pairs $\mathrm{nm}^{-2}$. The gray bars indicate the location of the inner surfaces of MMT oxygen atoms. For clarity, the number densities of nitrogen anions are multiplied by 10 in (A), by 5 in (B), by 40 in (C), and by 10 in (D).

position being the one where it can maximize its coordination by cations as well as its distance from the negatively charged MMT surfaces. When ten $\mathrm{C}_{1} \mathrm{C}_{1} \mathrm{C}_{1} \mathrm{NC}_{4}-\mathrm{NTf}_{2}$ ion pairs per interlayer $\left(0.336 \mathrm{C}_{1} \mathrm{C}_{1} \mathrm{C}_{1} \mathrm{NC}_{4}-\mathrm{NTf}_{2}\right.$ ion pair $\left.\mathrm{nm}^{-2}\right)$ are added, the single layer of cation head groups observed in the modified MMT splits into two distinct layers close to the MMT slab. Due to the larger amount of liquid, the ions cannot remain in a single layer, and the structure is dictated by the repulsion between the negatively charged surface of the clay and the anions. The latter sit in the middle of the interlayer, and the cations split into two groups on each side of them, as can be seen in figure $3(\mathrm{C})$. With $0.336 \mathrm{C}_{1} \mathrm{C}_{1} \mathrm{C}_{1} \mathrm{NC}_{10}-\mathrm{NTf}_{2}$ ion pairs $\mathrm{nm}^{-2}$ (figure 4(D)), the interlayer space increases, but the structuring of ions is preserved in comparison with the system with a lower density (figure 4(B)).

\subsection{Structure of $C_{1} C_{1} C_{1} N C_{4}$ organo-modified MMT with high IL content}

Figure 4 shows number density profiles calculated for the MMT modified with $\mathrm{C}_{1} \mathrm{C}_{1} \mathrm{C}_{1} \mathrm{NC}_{4}$. With fifty ion pairs (or $0.84 \mathrm{C}_{1} \mathrm{C}_{1} \mathrm{C}_{1} \mathrm{NC}_{4}-\mathrm{NTf}_{2} \mathrm{~nm}^{-2}$ ), the ion structuring remains as in the case of 0.336 ion pairs $\mathrm{nm}^{-2}$ (figure $4(\mathrm{~A})$ ). When additional ion pairs are included (one hundred ion pairs or $1.68 \mathrm{C}_{1} \mathrm{C}_{1} \mathrm{C}_{1} \mathrm{NC}_{4}-\mathrm{NTf}_{2} \mathrm{~nm}^{-2}$ ), the anions themselves have to split into two layers for packing reasons, and a third layer of cation head groups appears between them.

Perkin et al have investigated, by means of surface force balance (SFB) experiments, a pyrrolidinium-based ionic liquid confined between mica surfaces [43]. It is tempting to compare our results with their findings, although the systems are relatively different: while the ionic liquids do not differ much, the negative charge at the surface of mica is much larger, by a factor of 2.66, than that at the surface of MMT. They found out that the two thinnest films of butyl, hexyl, or octyl pyrrolidinium-based ionic liquids obtained in these experiments have thicknesses of 1.4 and $2.4 \mathrm{~nm}$. Based on the ion dimensions the authors propose that films of 1.4 and $2.4 \mathrm{~nm}$ width correspond to three (cation-anion-cation) and five (cation-anion-cation-anioncation) ion layers (see figure 3 of [43]). This interpretation is largely consistent with the present ones, as depicted in figure 4. Such a charge ordering is also consistent with the behavior of molten salts and ionic liquids at the surface of charged electrodes, a feature that is related in this context to overscreening of the charge by the first ion layer [11, 63, 64].

In addition to this Coulomb ordering, Perkin et al have also propose that negligible or no apolar-apolar interactions occur between butyl chains of cations, contrary to other systems that they have studied, in which they have observed monolayers or bilayers of alkyl chains [43, 65, 66]. We have therefore tried to further investigate this point in our simulations. For this purpose, we have studied the number densities of butyl chains. We have separated the total contribution into two or three groups, for densities of 0.84 and 1.68 ion pair $\mathrm{nm}^{-2}$, respectively, depending on the head group to which the butyl chain belongs. In the two studied cases, one can observe on figures 4(B) and (D) that a larger density of butyl chains occurs in the $z$ range where the density of head groups is also large (figures 4(A) and (C), respectively). This clearly shows that for the $\mathrm{C}_{1} \mathrm{C}_{1} \mathrm{C}_{1} \mathrm{NC}_{4}$-based ILs, there is no ordering of the apolar butyl chains in our simulations, in agreement with the experimental results of Perkin et al [43]. Note that, the narrower densities closest to both MMT slabs indicate that butyl chains are mostly aligned parallel to the MMT basal plane.

In order to illustrate further the Coulomb ordering and the absence of ordering of the apolar groups, figure 5 shows snapshots of ions in the interlayer space of MMT. For clarity, only 

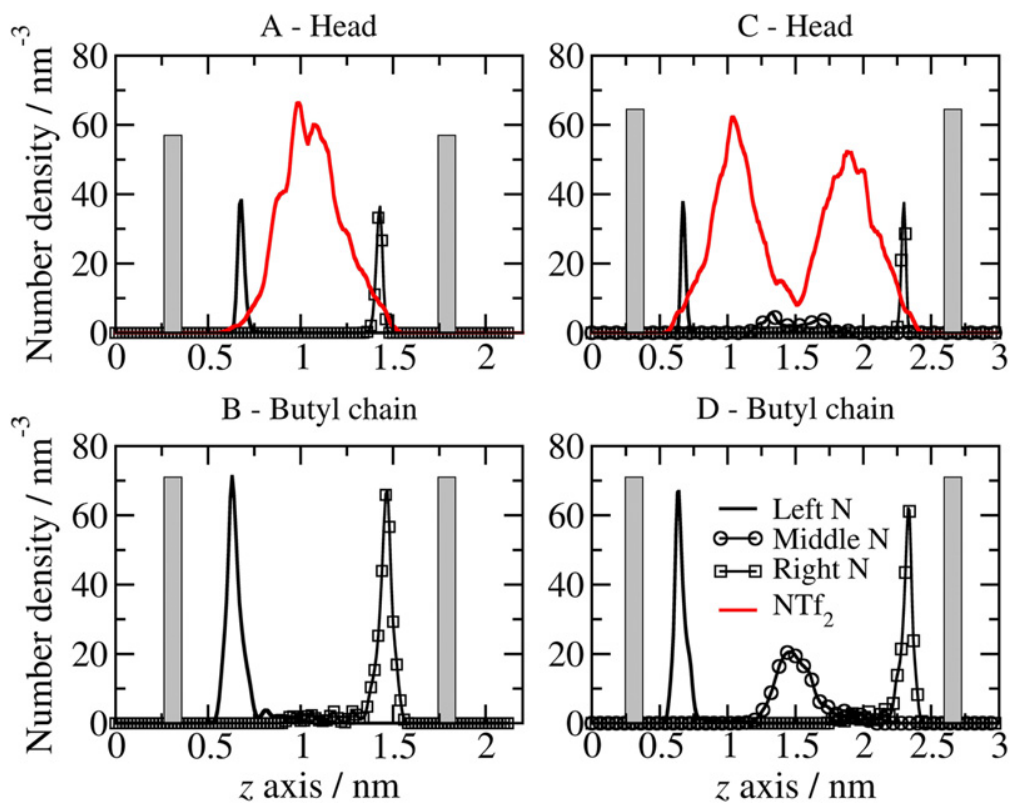

Figure 4. (A) and (C) Number density profiles of the nitrogen atom of cation head groups (black) and all atoms of NTf $\mathrm{N}_{2}$ anions (red) with densities of $0.84(\mathrm{~A})$ and $1.68(\mathrm{C}) \mathrm{C}_{1} \mathrm{C}_{1} \mathrm{C}_{1} \mathrm{NC}_{4}-\mathrm{NTf}_{2}$ ion pairs $\mathrm{nm}^{-2}$. Reported results are averaged over the two interlayer spaces. (B) and (D) Number density profiles of the butyl chain with densities of 0.84 (A) and 1.68 (C) $\mathrm{C}_{1} \mathrm{C}_{1} \mathrm{C}_{1} \mathrm{NC}_{4}-\mathrm{NTf}_{2}$ ion pairs nm ${ }^{-2}$. Full line and full line plus squares in (B) and (D) stand for butyl chains bonded to the nitrogen atom of head groups close to the left and right surface of MMT, respectively. (D) Full line plus circles stands for butyl chains bonded to the nitrogen atom of head groups in the middle of the interlayer space.
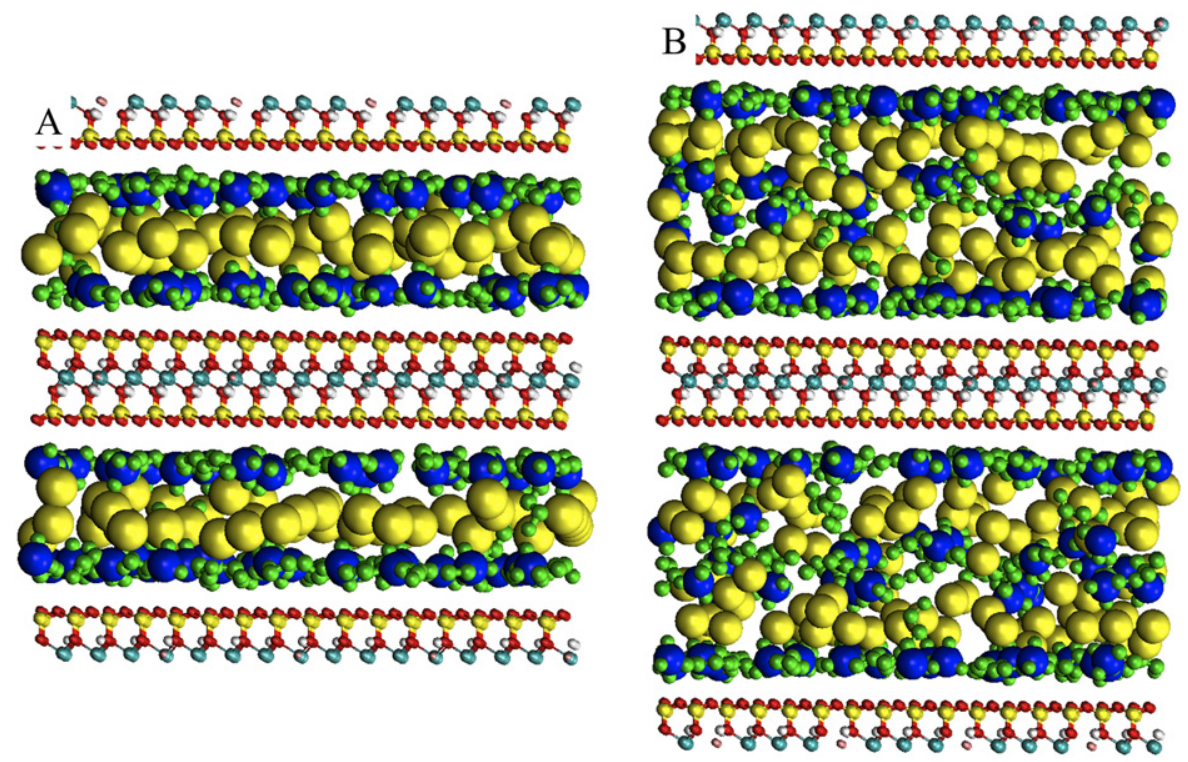

Figure 5. Snapshots of simulation cells, showing the layering of ions in the confined space of modified MMT with densities of 0.84 (A) and 1.68 (B) $\mathrm{C}_{1} \mathrm{C}_{1} \mathrm{C}_{1} \mathrm{NC}_{4}-\mathrm{NTf}_{2}$ ion pairs $\mathrm{nm}^{-2}$. Blue, green, and yellow spheres are the nitrogen atom of cations, $\mathrm{CH}_{2} / \mathrm{CH}_{3}$ groups, and sulfur atoms of anions, respectively. The $z$ axis corresponds to the direction perpendicular to the basal surface.

the sulfur atoms of anions are shown. With $0.84 \mathrm{C}_{1} \mathrm{C}_{1} \mathrm{C}_{1} \mathrm{NC}_{4}$ $\mathrm{NTf}_{2}$ ions pairs per $\mathrm{nm}^{-2}$ (figure $5(\mathrm{~A})$ ), one clearly sees one layer of ammonium heads close to each clay surface and a broader layer of anions in between, with an interlayer spacing of $1.47 \mathrm{~nm}$. When the number of ion pairs is doubled, the confining space increases to $2.35 \mathrm{~nm}$. Three layers of ammonium heads and two alternating layers of anions appear in figure 5(B). The alkyl chains of distinct layers of cations do not share the same region along the $z$ direction, indicating that there is no formation of apolar domains along this axis.

\subsection{Structure of $C_{1} C_{1} C_{1} N C_{10}$ organo-modified MMT with high IL content}

Figure 6 shows the number densities in the $\mathrm{C}_{1} \mathrm{C}_{1} \mathrm{C}_{1} \mathrm{NC}_{10^{-}}$ based systems, in the case of $0.84 \mathrm{C}_{1} \mathrm{C}_{1} \mathrm{C}_{1} \mathrm{NC}_{10}-\mathrm{NTf}_{2}$ ion 

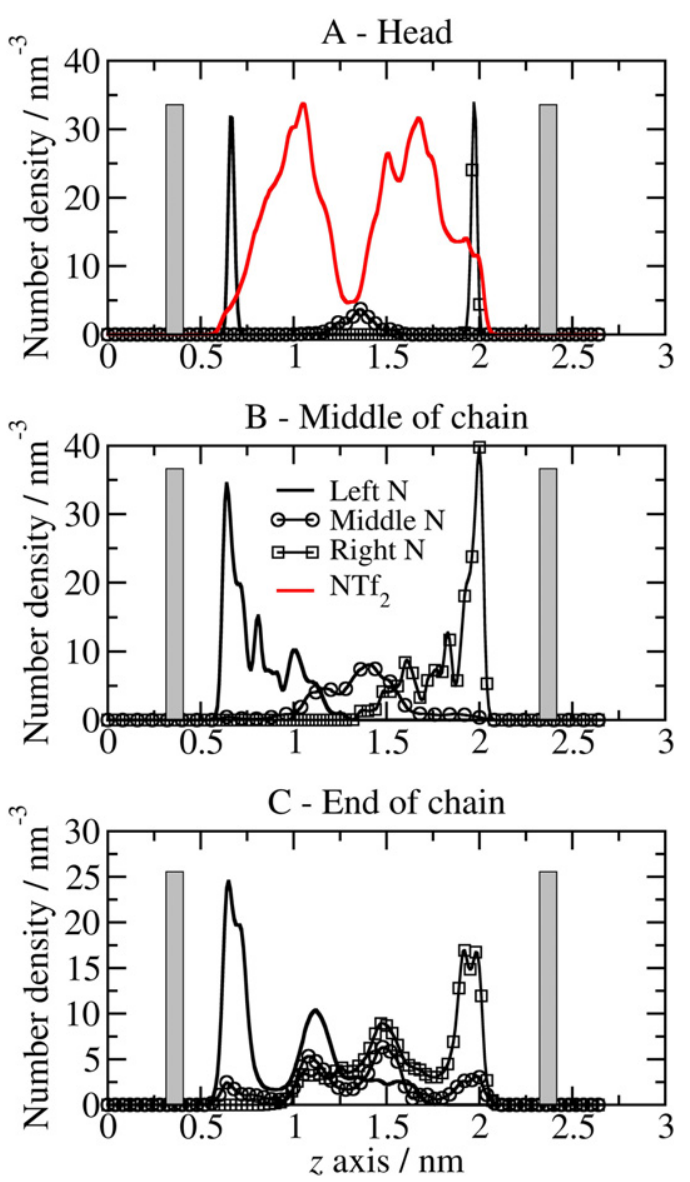

Figure 6. (A) Number density profiles of the nitrogen atom of cation head groups and all atoms of $\mathrm{NTf}_{2}$ anions (A) in MMT with 0.84 $\mathrm{C}_{1} \mathrm{C}_{1} \mathrm{C}_{1} \mathrm{NC}_{10}-\mathrm{NTf}_{2}$ ion pairs $\mathrm{nm}^{-2}$. The reported results are averaged over the two interlayer spaces. (B) and (C) Number density profiles of the decyl middle chain (the five carbon atoms closest to the nitrogen atom) and the decyl end chain (the five carbon atoms furthest from the nitrogen atom). Full line and full line plus squares in (B) and (C) stand for atoms of the decyl chain bonded to nitrogen atoms of head groups close to the left and right surfaces of MMT, respectively. Full line plus circles stands for atoms of the decyl chain bonded to the nitrogen atom of head groups in the middle of the interlayer space.

pairs $\mathrm{nm}^{-2}$. The basal spacing of modified MMT increases to $2.01 \mathrm{~nm}$ and the ions assemble in five ionic layers along the $z$ axis (figure 6(A)). For the head groups of the cations, two narrow peaks are observed, corresponding to ions lying close to the MMT negative surfaces, while a third peak appears in the middle of the interlayer. For the anions, two peaks are observed, each of them being located between those of the cation head groups. Note that this ionic assembly is similar to the one obtained for a density of $1.68 \mathrm{C}_{1} \mathrm{C}_{1} \mathrm{C}_{1} \mathrm{NC}_{4}-\mathrm{NTf}_{2}$ ion pairs $\mathrm{nm}^{-2}$ in an interlayer space of $2.35 \mathrm{~nm}$. The only difference is the height of the peaks of the $\mathrm{NTf}_{2}$ number density, which is approximately half that in figure 4(C). This structure is again in excellent qualitative agreement with the SFB experiments of Perkinet al [43] for an analogous system consisting of pyrrolidinium-based ionic liquid, with a decyl chain cation, between mica surfaces.

Perkin et al [43, 63] further reported, contrary to the $\mathrm{C}_{1} \mathrm{C}_{1} \mathrm{C}_{1} \mathrm{NC}_{4}-\mathrm{NTf}_{2}$ case, the formation of apolar domains in which the alkyl chains of the cations from successive layers adopt an interdigitated structure [43, 66]. We have therefore again split the cations alkyl chains number density contributions into two: the first corresponding to carbons from the central part of the chain (corresponding to the five carbon atoms closest to the nitrogen atom) and the second corresponding to carbons from the end of the chain. These alkyl number densities are respectively shown in figures 6(B) and (C). Again, we have labeled them according to the layer to which the nitrogen atom belongs. We can clearly see that the atoms from the middle of the chain belonging to one cation layer lie in the same regions as those from the end of the chain of the neighboring layer. Our simulations therefore show that the picture of apolar domains consisting of interdigitated layers proposed by Perkin et al [43] for ammonium cations with a large alkyl chain remains valid when passing from highly charged mica surfaces to MMT. Heinzet al [58, 60], investigating the effect of the clay surface charge, showed that when MMT has higher surface charge, the cations tend to adopt a conformation in which the alkyl chains align perpendicular to the MMT slab. Therefore, the interdigitation of alkyl chains suggested by Perkinet al [43] may be even stronger in mica than in MMT. In spite of the confining effect, the appearance of apolar domains is determined by the alkyl chain size, as in similar neat tetraalkylammonium-based ionic liquids [49].

The snapshot shown in figure 7(A), illustrates the structure of this system with a density of $0.84 \mathrm{C}_{1} \mathrm{C}_{1} \mathrm{C}_{1} \mathrm{NC}_{10}-\mathrm{NTf}_{2}$ ion pairs $\mathrm{nm}^{-2}$ confined in MMT. The clustering of green spheres, which represent the decyl chain, illustrates the apolar domains indicated by the number densities discussed above.

When additional $\mathrm{C}_{1} \mathrm{C}_{1} \mathrm{C}_{1} \mathrm{NC}_{10}-\mathrm{NTf}_{2}$ ion pairs are included in the system, the structure becomes more disordered, as illustrated in figure 7(B), and the layering is less obvious. There is now enough ionic liquid to screen almost entirely the MMT surface charge [67], and it can now adopt a bulk-like structure in the middle of the interlayer. Of course, for a larger surface charge, we expect that the amount of ionic liquid needed to reach this behavior would also have to be larger, and this is indeed what happens in the case of mica, for which a slight layering is still observed [43, 66].

\subsection{On the swelling of MMT by ILs}

It is well known that cationic clays can easily swell in water and their swelling behavior has been the subject of molecular simulation studies [68, 69]. While a full analysis of the relative stability of the different hydration states requires the computation of swelling-free energies, which is out of the scope of the present work, a first indication can be obtained by evaluating the hydration energy:

$$
\Delta E(N)=\frac{\langle U(N)\rangle-\langle U(0)\rangle}{N}
$$

where $N$ is the number of water molecules, $\langle U(N)\rangle$ is the average potential energy of $N$ water molecules on the surface of an equilibrated system and $\langle U(0)\rangle$ is the average potential energy of a reference surface without any water [68, 69]. Here, we use the same expression to estimate the relative 


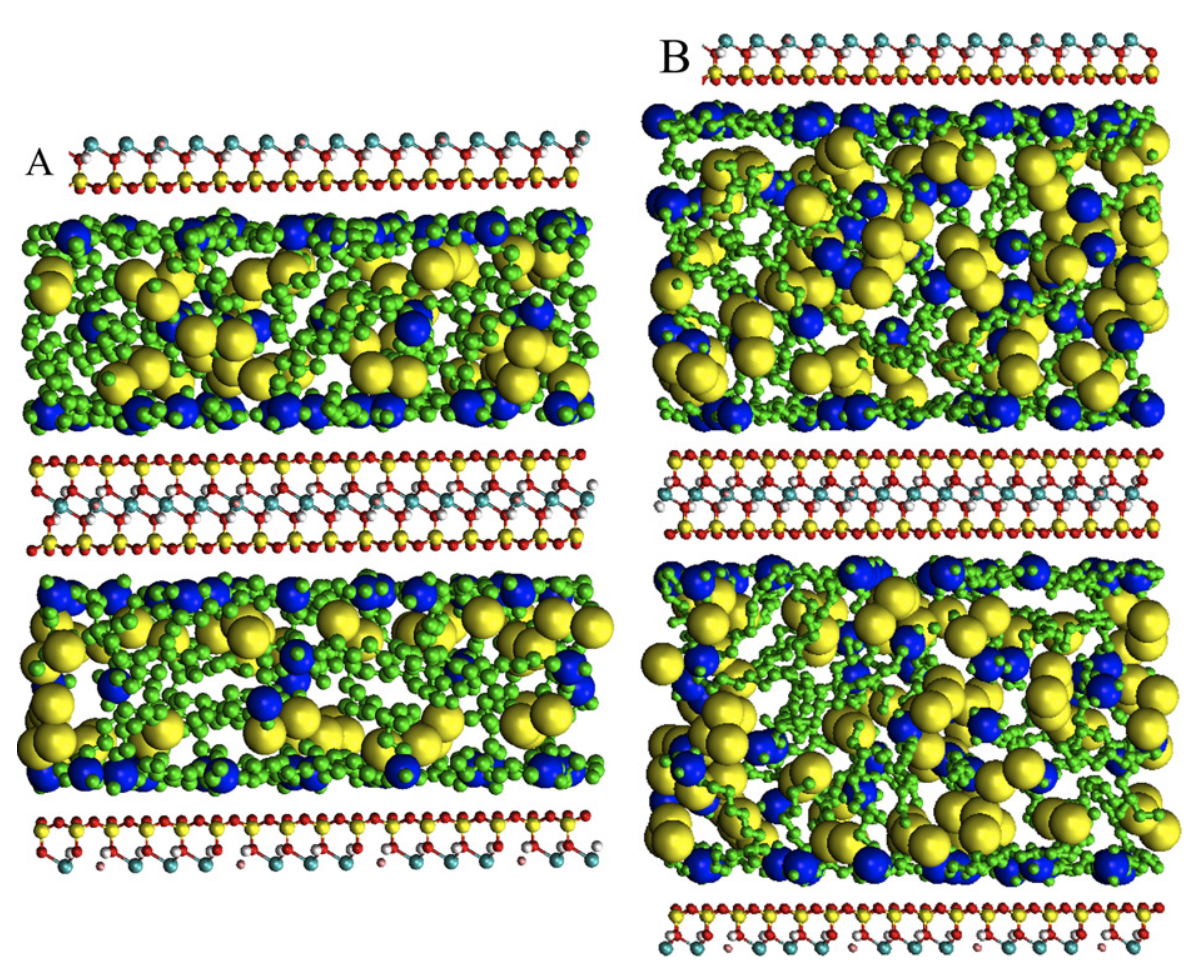

Figure 7. Snapshots of simulation cells, showing the layering of ions in the confined space of modified MMT with 0.84 (A) and 1.68 (B) $\mathrm{C}_{1} \mathrm{C}_{1} \mathrm{C}_{1} \mathrm{NC}_{10}-\mathrm{NTf}_{2}$ ion pairs $\mathrm{nm}^{-2}$. Blue, green, and yellow spheres are the nitrogen atom of cations, $\mathrm{CH}_{2} / \mathrm{CH}_{3}$ groups, and sulfur atoms of anions, respectively. The $z$ axis corresponds to the direction perpendicular to the basal surface.
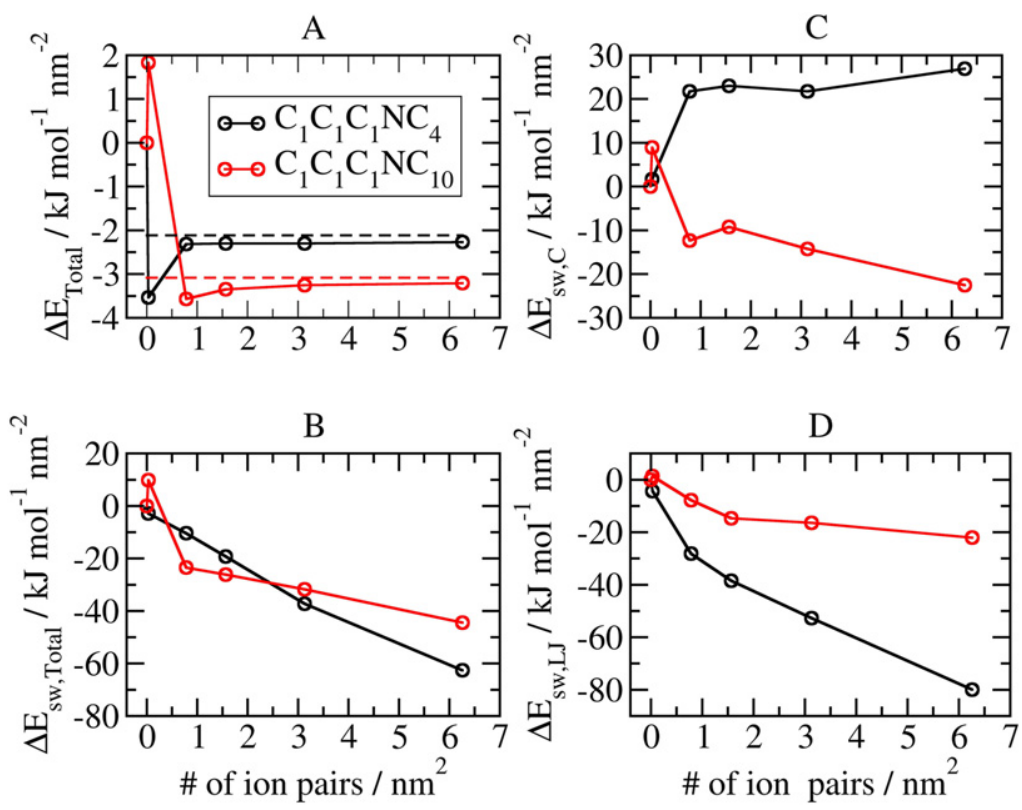

Figure 8. Total ((A)—from equation (2), (B)—from equation (3)), Coulomb ((C)—from equation (3)), and Lennard-Jones ((D)—from equation (3)) energies. The dashed lines are the total energy of neat ionic liquids, which is normalized by the internal surfaces of MMT to allow graphical comparison.

thermodynamic stability of the ionic liquids in the interlayer space of modified MMT, now with $N$ the number of ion pairs, $\langle U(N)\rangle$ the average energy of $N$ ion pairs on the surface of an equilibrated system, and $\langle U(0)\rangle$ the average energy of a reference surface of MMT modified with the respective cations. Figure 8(A) shows the total energy as calculated by equation (2) normalized by the total surface as a function of the density of ion pairs $\mathrm{nm}^{-2}$. At the lowest considered number of ion pairs $\mathrm{nm}^{-2}$, the total energy for $\mathrm{C}_{1} \mathrm{C}_{1} \mathrm{C}_{1} \mathrm{NC}_{4}-\mathrm{NTf}_{2}$ is around $3.5 \mathrm{~kJ} \mathrm{~mol}^{-1} \mathrm{~nm}^{-2}$ lower than the energy of $\mathrm{C}_{1} \mathrm{C}_{1} \mathrm{C}_{1} \mathrm{NC}_{4}$-exchanged. Conversely, at the same density of $\mathrm{C}_{1} \mathrm{C}_{1} \mathrm{C}_{1} \mathrm{NC}_{10}-\mathrm{NTf}_{2}$, the total energy is around 
$2 \mathrm{~kJ} \mathrm{~mol}^{-1} \mathrm{~nm}^{-2}$ higher than $\mathrm{C}_{1} \mathrm{C}_{1} \mathrm{C}_{1} \mathrm{NC}_{10}$-exchanged. For both cations, at a high density of ionic liquids, the total energy calculated by equation (2) tends towards the total energy of the respective neat ionic liquids (dashed lines). Note that for comparison purposes, the bulk energies are also normalized by the internal surface areas of MMT.

Alternatively, one can evaluate the stability of a system by calculating the swelling energy, which is the difference between the final and initial state energies. Figure 8(B) shows the swelling energy,

$$
\Delta E_{s w}=\frac{\langle U(N)\rangle-\left[\langle U(0)\rangle+N\left\langle U_{\mathrm{Bulk}}(1 I L)\right\rangle\right]}{A}
$$

where $N$ is the number of ion pairs, $\langle U(N)\rangle$ is the average energy of $N$ ion pairs on the surface of an equilibrated system, $\langle U(0)\rangle$ is the average energy of a reference surface of MMT modified with the respective cations, $A$ is the total internal surface area, and $\langle U(1 I L)\rangle$ is the bulk energy per ion pair. The presence of one $\mathrm{C}_{1} \mathrm{C}_{1} \mathrm{C}_{1} \mathrm{NC}_{4}-\mathrm{NTf}_{2}$ ion pair forces the system to a lower energy, whereas in the case of $\mathrm{C}_{1} \mathrm{C}_{1} \mathrm{C}_{1} \mathrm{NC}_{10}-\mathrm{NTf}_{2}$, the system has around $10 \mathrm{~kJ} \mathrm{~mol}^{-1} \mathrm{~nm}^{-2}$ higher energy than the initial states. This suggests that the insertion of a few ion pairs is energetically favorable in the former case, and unfavorable in the latter. At a larger number of ion pairs both systems have lower energy than the initial states, indicating that the swelling of the organo-modified MMT by the corresponding IL is energetically favorable.

The total energy is the sum of Coulomb, Lennard-Jones and intramolecular energies. We further investigate the energetics of swelling by inspecting of Coulomb and LennardJones energies, which are shown in figures $8(C)$ and (D), respectively. The Coulomb contribution to the swelling energy in $\mathrm{C}_{1} \mathrm{C}_{1} \mathrm{C}_{1} \mathrm{NC}_{4}-\mathrm{NTf}_{2}$ is always positive, seeming to reach a plateau at a high number of ion pairs. In the case of $\mathrm{C}_{1} \mathrm{C}_{1} \mathrm{C}_{1} \mathrm{NC}_{10}-\mathrm{NTf}_{2}$, this contribution follows the same behavior, except for the lowest IL content, for which it becomes positive (figure $8(\mathrm{C})$ ). The Lennard-Jones energy in both ionic liquids is always negative, except for one $\mathrm{C}_{1} \mathrm{C}_{1} \mathrm{C}_{1} \mathrm{NC}_{10}-\mathrm{NTf}_{2}$ ion pair. Hence, the total swelling energy mainly results from the balance of the Coulomb and Lennard-Jones contributions.

Heinz et al $[59,60]$ studied the cleavage energy of MMT modified with tetraalkylammonium cations by molecular dynamics simulations. The authors observed that the trimethylbutylammonium cation has the highest cleavage energy, whereas the modifying cation bearing a decyl chain has a lower cleavage energy in MMT with CEC $=91 \mathrm{meq} / 100 \mathrm{~g}$. The highest cleavage energy found in trimethylbutylammonium is related to the energy needed to break one layer of cations and to create two layers of cations adsorbed onto the MMT surfaces. In the case of trimethyldecylammonium, as two layers of cations already exist in the interlayer space, the energy to pull the MMT slabs apart is lower. Therefore, the positive and negative Coulomb contributions to the swelling energy in both ionic liquids are consistent with the cleavage energies of MMT modified with these two cations. Although the cleavage energy of MMT modified with $\mathrm{C}_{1} \mathrm{C}_{1} \mathrm{C}_{1} \mathrm{NC}_{10}$ cations is lower, the inclusion of one ion pair in each interlayer space leads to system positive energies, meaning that presence of an ion pair in the confining space is not favorable because it is located in an apolar environment, as shown in figure 3(B).

\section{Conclusions}

In conclusion, we have studied via molecular dynamics simulations the behavior of two ionic liquids, formed by either $\mathrm{C}_{1} \mathrm{C}_{1} \mathrm{C}_{1} \mathrm{NC}_{4}$ or $\mathrm{C}_{1} \mathrm{C}_{1} \mathrm{C}_{1} \mathrm{NC}_{10}$ cations associated with the bis[(trifluoromethane)sulfonyl]amide $\left(\mathrm{NTf}_{2}\right)$ anion, in the interlayer space of modified MMT clays. Strong variations in the organization of the ionic liquids have been observed depending on the chain length of the cation and its density inside the interlayer. In general, the structure is dominated by the Coulomb repulsion between the negatively charged basal surface of the MMT and the anions, which is at the origin of the strong layering of the ionic liquid. In addition to this Coulomb ordering, we have observed the formation of apolar domains with interdigitated alkyl chains in the case of the $\mathrm{C}_{1} \mathrm{C}_{1} \mathrm{C}_{1} \mathrm{NC}_{10}$-based ionic liquid; in the case of $\mathrm{C}_{1} \mathrm{C}_{1} \mathrm{C}_{1} \mathrm{NC}_{4}$ such domains do not form because the alkyl chains are too short. These results are in excellent qualitative agreement with the SFB experiments by Perkin et al, in which a similar behavior was observed when confining analogous ionic liquids between surfaces of mica, which carries a more strongly charged surface than MMT.

From the energetic point of view, we have showed that the insertion of a few ion pairs in the interlayer of organomodified MMT with the same cation can be either energetically favorable or unfavorable depending on the length of the alkyl chain. However, the swelling of the organo-modified MMT caused by a large amount of ionic liquid seems energetically favorable in all cases.

\section{Acknowledgments}

MS is grateful to the FAPESP for a visiting researcher grant (2013/01382-4), which enabled this collaboration. LJAS acknowledge FAPESP (2008/08670-7). DD thanks CNPq for a scholarship.

\section{References}

[1] Nicolosi V, Chhowalla M, Kanatzidis M G, Strano M S and Coleman J N 2013 Science 3401226419

[2] Bergaya F, Theng B K G and Lagaly G 2006 Handbook of Clay Science vol 1 (Amsterdam: Elsevier)

[3] Carretero M I and Pozo M 2010 Appl. Clay Sci. 47171

[4] de Paiva L B, Morales A R and Díaz F R V 2008 Appl. Clay Sci. 428

[5] LeBaron P C, Wang Z and Pinnavaia T J 1999 Appl. Clay Sci. 1511

[6] Alexandre M and Dubois P 2000 Mater. Sci. Eng. 281

[7] Ding Y, Guo C, Dong J-Y and Wang Z 2006 Appl. Polym. Sci. 1024314

[8] Livi S, Duchet-Rumeau J, Pham T N and Gerad J F 2010 J. Colloid Interface Sci. 349424

[9] Fontana J P, Camilo F F, Bizeto M A and Faez R 2013 Appl. Clay Sci. 83/84 203

[10] Mezger M et al 2008 Science 322424

[11] Merlet C, Rotenberg B, Madden P A and Salanne M 2013 Phys. Chem. Chem. Phys. 1515781

[12] Perkin S 2012 Phys. Chem. Chem. Phys. 145052

[13] Lovelock K R J 2012 Phys. Chem. Chem. Phys. 145071 
[14] Baldelli S 2013 J. Phys. Chem. Lett. 4244

[15] Mendonça A C F, Malfreyt P and Padua A A H 2012 J. Chem. Theory Comput. 83348

[16] Mendonça A C F, Padua A A H and Malfreyt P 2013 J. Chem. Theory Comput. 91600

[17] Pensado A S and Padua A A H 2011 Angew. Chem. Int. Edn $\mathbf{5 0} 8683$

[18] Lynden-Bell R M, Frolov A I and Fedorov M V 2012 Phys. Chem. Chem. Phys. 142693

[19] Galinski M, Lewandowski A and Stepniak I 2006 Electrochim. Acta 515567

[20] Zakeeruddin S M and Gratzel M 2009 Adv. Funct. Mater. 192187

[21] Armand M, Endres F, Macfarlane D R, Ohno H and Scrosati B 2009 Nature Mater. 8621

[22] Delahaye E, Xie Z, Schaefer A, Douce L, Rogez G, Rabu P, Günter C, Gutmann J S and Taubert A 2011 Dalton Trans 409977

[23] Wang H, Zou M, Li N and Li K 2007 J. Mater. Sci. 427738

[24] Hu H, Martin J C, Xiao M, Southworth C S, Meng Y and Sun L 2011 J. Phys. Chem. C 1155509

[25] Kong A, Ding Y J, Wang P, Zhang H Q, Yang F and Shan Y K 2011 J. Solid State Chem. 184331

[26] Sutto T E and Duncan T T 2012 Electrochim. Acta 77204

[27] Letaief S and Detellier C 2007 J. Mater. Chem. 171476

[28] Gilman J W et al 2002 Chem. Mater. 143776

[29] Morgan A B and Harris J D 2004 Polymer 458695

[30] Awad W H, Gilman J W, Nyden M, Harris R H, Sutto T E Jr, Callahan J, Trulove P C, DeLong H C and Fox D M 2004 Thermochim. Acta 4093

[31] Chigwada G, Wang D and Wilkie C A 2006 Polym. Degrad. Stab. 91848

[32] Kim N H, Malhotra S V and Xanthos M 2006 Microporous Mesoporous Mater. 9629

[33] Takahashi C, Shirai T and Fuji M 2012 Mater. Chem. Phys. 135681

[34] Ha J U and Xanthos M 2011 Green Chem. Lett. Rev. 2011103

[35] Siqueira L J A, Constantino V R L, Camilo F F, Torresi R M, Temperini M L A, Ribeiro M C C and Izumi C M S 2014 Spectrochim. Acta A 122469

[36] Letaief S and Detellier C 2005 J. Mater. Chem. 154734

[37] Letaief S, Elbokl T A and Detellier C 2006 J. Colloid Interface Sci. $\mathbf{3 0 2} 254$

[38] Takahashi C, Hata H and Kuroda K 2010 Chem. Mater. 223340

[39] Letaief S, Diaco T, Pell W, Gorelsky S I and Detellier C 2008 Chem. Mater. 207136

[40] Tonle I K, Letaief S, Ngameni E and Detellier C 2009 J. Mater. Chem. 195996
[41] Dedzo G K, Letaief S and Detellier C 2012 J. Mater. Chem. 2220593

[42] Tambach T J, Boek E S and Smit B 2006 Phys. Chem. Chem. Phys. 82700

[43] Smith A M, Lovelock K R J, Gosvami N N, Licence P, Dolan A, Welton T and Perkin S 2013 J. Phys. Chem. Lett. 4378

[44] Marry V, Rotenberg B and Turq P 2008 Phys. Chem. Chem. Phys. 104802

[45] Rotenberg B, Marry V, Malikova N and Turq P 2010 J. Phys.: Condens. Matter 22284114

[46] Cygan R T, Liang J-J and Kalinichev A G 2004 J. Phys. Chem. B 1081255

[47] Siqueira L J A and Ribeiro M C C 2007 J. Phys. Chem. B 11111776

[48] Siqueira L J A and Ribeiro M C C 2009 J. Phys. Chem. B 1131074

[49] Siqueira L J A and Ribeiro M C C 2011 J. Chem. Phys. 135204506

[50] Figueiredo P H, Siqueira L J A and Ribeiro M C C 2012 J. Phys. Chem. B 11612319

[51] Das J, Eun C, Perkin S and Berkowitz M L 2011 Langmuir 2711737

[52] Tieleman D P and Berendsen H J C 1996 J. Chem. Phys. $\mathbf{1 0 5} 4871$

[53] Salanne M and Madden P A 2011 Mol. Phys. 1092299

[54] Schroder C 2012 Phys. Chem. Chem. Phys. 143089

[55] Siqueira L J A, Urahata S M and Ribeiro M C C 2003 J. Chem. Phys. 1198002

[56] Martinez J M and Martinez L 2003 J. Comput. Chem. 24819

[57] Smith W and Forester T R 1995 The DLPOLY2 User Manual (Daresbury: CCLRC, Daresbury Laboratory)

[58] Heinz H, Vaia R A, Krishnamoorti and Farmer B L 2007 Chem. Mater. 1959

[59] Fu Y-T and Heinz H 2010 Chem. Mater. 221595

[60] Fu Y-T and Heinz H 2010 Phil. Mag. 9017

[61] Pinilla C, Del Pópolo M G, Kohanoff J and Lynden-Bell R M 2007 J. Phys. Chem. B 1114877

[62] Fedorov M V and Lynden-Bell R M 2012 Phys. Chem. Chem. Phys. 142552

[63] Lanning O and Madden P A 2004 J. Phys. Chem. B 10811069

[64] Kornyshev A A 2007 J. Phys. Chem. B 205545

[65] Perkin S, Crowhurst L, Niedermeyer H, Welton T, Smith A M and Gosvami N N 2011 Chem. Commun. 476572

[66] Smith A M, Lovelock K R J and Perkin S 2013 Faraday Discuss 167279

[67] Perkin S, Salanne M, Madden P and Lynden-Bell R 2013 Proc. Natl Acad. Sci. USA 110 E4121

[68] Smith D E 1998 Langmuir 145959

[69] Wang J, Kalinichev A G, Kirkpatrick R J and Cygan R T 2005 J. Phys. Chem. B 10915893 